\title{
Development and Validation of Reverse Phase Chiral HPLC Method for Quantification of Enantiomer in Lamivudine Drug Substance
}

Section: Healthcare

ISI Impact Factor (2019-20): 1.628

IC Value (2019): 90.81 SJIF (2020) $=7.893$

(c) (1) (3)

Siva Jyothi $\mathbf{N}^{1}$, Venkatnarayana $\mathbf{M}^{1}$

Copyright@IJCRR

'Department of Chemistry, GITAM School of Science, GITAM (Deemed to be University), Rudraram, Hyderabad, Telangana, India.

\section{ABSTRACT}

Introduction: Chiral HPLC is a chromatographic separation technique used to separate the Enantiomer or Diastereomer from the main active compound.

Aim: A simple, rapid and robust reverse phase chiral HPLC method was developed and validated for the quantification of Lamivudine Enantiomer in Lamivudine drug substance.

Methodology: The Enantiomer of Lamivudine was resolved in Lux cellulose-5 column using a mobile phase containing Methanol: Diethylamine $(100: 0.1 \mathrm{v} / \mathrm{v})$ at a flow rate of $0.5 \mathrm{~mL} / \mathrm{min}$.

Results: The resolution between Enantiomer and Lamivudine was found to be more than 1.5 in an optimized method. The developed method was validated and proved that the method was specific, sensitive, accurate and precise as per ICH. The limit of detection and limit of quantification for Lamivudine Enantiomer was $0.004 \%$ and $0.012 \%$ respectively. The linearity curve was found to be linear and the correlation coefficient obtained was 0.999 . The average percentage recoveries of Enantiomer were in the range of 97 to $102 \%$.

Conclusion: The proposed method was found to be suitable and accurate for the quantitative determination of Enantiomer in Lamivudine drug substance.

Key Words: Enantiomer, Lamivudine, Reverse phase chiral HPLC, Lux cellulose-5 column, Sensitivity, Method development, Method validation, ICH guidelines

\section{INTRODUCTION}

Lamivudine is a reverse transcriptase inhibitor and zalcitabine analogue in which a sulfur atom replaces the 3 ' carbon of the pentose ring. It is used to treat Human Immunodeficiency Virus Type 1 (HIV-1) and hepatitis B (HBV). ${ }^{1}$ Lamivudine is chemically known as 4-Amino-1-[(2R,5S)2-(hydroxymethyl)-1,3-oxathiolan-5-yl]-1,2-dihydro pyrimidine-2-one, Its molecular formula $\mathrm{C}_{8} \mathrm{H}_{11} \mathrm{~N}_{8} \mathrm{O}_{3} \mathrm{~S}$ and the molecular weight is $229.3 \mathrm{gm} / \mathrm{mol} .{ }^{1}$ Lamivudine is generally called $3 \mathrm{TC}$ and is available as Epivir ${ }^{\circledR}$ and Epivir- $\mathrm{HBV}^{\circledR}$ as individual and available with the combination of drug Tenofovir. ${ }^{2}$ Lamivudine is an approved medicine by the U.S. Food and Drug Administration (FDA) for the treatment of HIV infection in adults and children 3 months of age and older. Lamivudine belongs to a group of HIV drugs called nucleoside reverse transcriptase inhibitors (NRTIs). NRTIs block an HIV enzyme called reverse transcriptase. By blocking reverse transcriptase, NRTIs prevent HIV from multiplying and can reduce the amount of HIV in the body. ${ }^{3}$ Lamivudine and Enantiomer structures are shown in Figure 1.

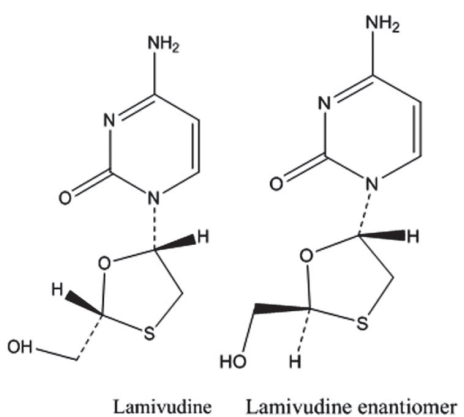

Figure 1: Chemical structures of Lamivudine and Enantiomer

Corresponding Author:

Venkatnarayana.Muvvala, Department of Chemistry, GITAM School of Science, GITAM (Deemed to be University), Rudraram, Hyderabad, Telangana, India; E-mail:vmuvvala2@gitam.edu

ISSN: 2231-2196 (Print)

Received: 24.01 .2021
ISSN: 0975-5241 (Online)

Revised: 12.03 .2021
Accepted: 09.05.2021

Published: 11.10 .2021 
The separation of Enantiomer has become very important in analytical chemistry especially in the pharmaceutical industry. In the literature survey, various methods are available for the determination of Lamivudine in combined dosage form quantification methods. . $^{4}$ An HPLC method was published with $0.3 \%$ of specification limit for the separation of Enantiomer in Lamivudine by using L45 column with $5 \mu \mathrm{m}$ to $10 \mu \mathrm{m}$ diameter column. ${ }^{10}$ In this method resolution between Enantiomer and Lamivudine peak was less. Another research paper was available for Lamivudine Enantiomer published with long runtime by using chiral HPLC. ${ }^{11}$ In this research work, a reverse phase chiral HPLC method was developed for resolving Enantiomer by considering $0.05 \%$ as specification limit along with short run time and validated the method according to ICH guidelines. ${ }^{12,13}$

\section{MATERIALS AND METHODS}

Lamivudine drug substance and related impurities were supplied by Synzeal laboratory limited. The HPLC grade methanol and Diethylamine procured from Merck chemicals limited.

\section{Instrumentation and Chromatographic condi- tions}

WATERS HPLC, Model: 2695 equipped with 2996 photodiode array detector with an automated sample injector was used for development and method validation, Lux cellulose-5, 250x $4.6 \mathrm{~mm}, 5 \mu \mathrm{m}$ column was used for the separation. $0.1 \%$ Diethylamine in methanol used as mobile phase as well as diluent. Analysis was carried out as isocratic mode with a flow rate of $0.5 \mathrm{~mL} / \mathrm{min}$ and the injection volume was $10 \mu \mathrm{L}$. The column temperature was $30^{\circ} \mathrm{C}$ and the run time was 12 minutes. The data were acquired at $270 \mathrm{~nm}$. The output signal was monitored and integrated using Empower 2 software.

\section{Sample solution Preparation}

Weighed and transferred $25 \mathrm{mg}$ of Lamivudine sample into $100 \mathrm{~mL}$ volumetric flask, dissolved in $30 \mathrm{~mL}$ of diluent by sonication and makeup to the volume with diluent, containing solution concentration was $0.25 \mathrm{mg} / \mathrm{mL}$.

\section{Enantiomer solution preparation (0.05\%)}

Stock Solution-1: $5 \mathrm{mg}$ of Enantiomer was weighed and transferred to $50 \mathrm{~mL}$ of volumetric flask and dissolved in 20 $\mathrm{mL}$ of diluent by sonication and made up to mark with diluents to give a stock solution- 1 containing $0.1 \mathrm{mg} / \mathrm{mL}$.

Stock Solution-2: Transferred $1 \mathrm{~mL}$ of stock solution-1 into a $10 \mathrm{~mL}$ volumetric flask diluted the volume with diluent to give a solution containing $10 \mu \mathrm{g} / \mathrm{mL}$ of Enantiomer.

\section{System suitability solution Preparation}

Weighed and transferred $25 \mathrm{mg}$ of Lamivudine sample into $100 \mathrm{~mL}$ volumetric flask dissolved in $50 \mathrm{~mL}$ of diluent by sonication, add $1.25 \mathrm{~mL}$ of Enantiomer stock solution-2 and made up to the volume with a diluent solution containing a concentration of $0.25 \mathrm{mg} / \mathrm{mL}$ of Lamivudine and 0.000125 $\mathrm{mg} / \mathrm{mL}$ of Enantiomer.

\section{METHOD VALIDATION}

\section{Specificity (Selectivity)}

Specificity is the ability to assess unequivocally the analyte in the presence of components that may be expected to be present in the impurities. There must be inarguable data for a method to be specific. Specificity measures only the desired component without interference from other species which might be present. The blank, system suitability solution and sample solutions were prepared as per methodology. Individual impurities prepared at $0.1 \mathrm{mg} / \mathrm{mL}$ and spike sample solutions have been made concerning specification limits. The retention time of all the injected analytes was recorded.

\section{Sensitivity}

The Limit of Detection is the minimum level at which the analyte can be reliably detected. The limit of quantitation is defined as the lowest amount or concentration of a drug substance which can be estimated with reproducible precision and accuracy under the optimized method conditions. LOD and LOQ were assessed by using the equations (1) and (2), respectively.

$$
\begin{aligned}
& \mathrm{LOD}=3.3 \sigma / \mathrm{S} \ldots \ldots \ldots . .(1) \\
& \mathrm{LOQ}=\mathbf{1 0} \sigma / \mathrm{S} \ldots \ldots \ldots \ldots . .
\end{aligned}
$$

Where,

$$
\begin{aligned}
& \sigma=\text { the standard deviation of the response (STEYX) } \\
& S=\text { the slope of the calibration curve }
\end{aligned}
$$

The slope $\mathrm{S}$ is estimated from the calibration curve of the analyte.

\section{Linearity}

The linearity of the method was demonstrated for Lamivudine and Enantiomer by analyzing the solutions ranging from LOQ to $150 \%$ of the specification limit. The correlation coefficient for Enantiomer and Lamivudine was assessed.

\section{Precision}

\section{Precision at $L O Q$}

The precision at LOQ level was confirmed by assessing the $\%$ RSD of peak areas of the six repeated injections of 
Lamivudine and Enantiomer solution having LOQ level concentration.

\section{System Precision}

The system precision of the current method was performed by injecting 100\% level of Lamivudine standard solution in six replicates.

\section{Method Precision}

The precision of the method was determined by analyzing six individual samples of Lamivudine spiked with Enantiomer at $100 \%$ of the specification limit.

\section{Accuracy}

The accuracy of the method was determined percentage recovery method, using solutions containing Lamivudine sample spiked with Enantiomer at LOQ, 50\%, 100\% and 150\% of the working strength of Lamivudine. All the solutions were prepared in triplicate and analyzed.

\section{Robustness}

It was determined by slightly changing the chromatographic method conditions intentionally. The robustness of the present method was evaluated by making the intentional changes to flow rate $( \pm 10 \%)$, column oven temperature $\left( \pm 5^{\circ} \mathrm{C}\right)$ and wavelength $( \pm 3 \mathrm{~nm})$ of the actual method conditions.

\section{RESULTS}

\section{Optimization method}

Lamivudine and its Enantiomer were effectively separated by a method consisting of a Lux cellulose-5 (250x $4.6 \mathrm{~mm}, 5 \mu \mathrm{m})$ column and. $0.1 \%$ Diethyl amine in methanol as a mobile phase which pumping in isocratic mode with a flow rate of $0.5 \mathrm{~mL} / \mathrm{min}$. The eluents were detected at $270 \mathrm{~nm}$ wavelength. The retention time of Lamivudine and its Enantiomer were observed at $7.8 \mathrm{~min}$ and $7.2 \mathrm{~min}$ respectively with acceptable resolution. The chromatogram is shown in Figure 2.

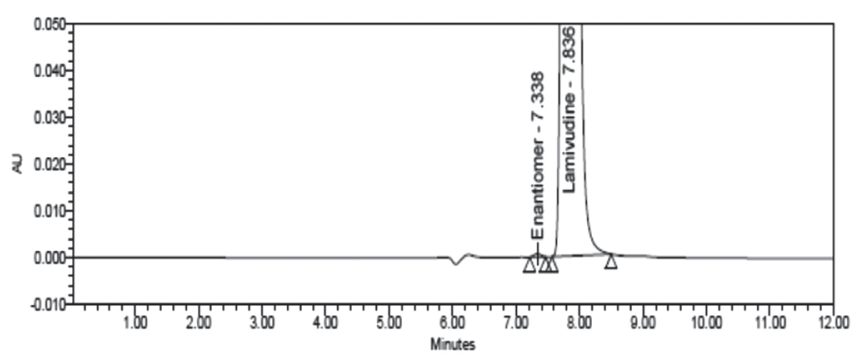

Figure 2: Optimized method Chromatogram of Lamivudine and its Enantiomer.

\section{Method Validation}

\section{Specificity (Selectivity)}

Based on the obtained results, all impurities eluted at different retention times and adequately resolved each other and also from main peak. Representative chromatogram was shown in Figure 3. Hence method has good specificity as per ICH guidelines.

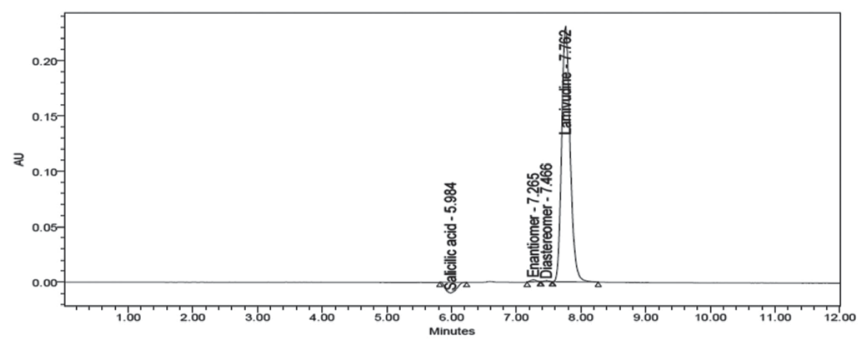

Figure 3: A typical representative HPLC chromatogram of the spiked sample.

\section{Sensitivity}

The LOD and LOQ values of Lamivudine and its Enantiomer were calculated as $0.0001 \mathrm{mg} / \mathrm{mL}$ and $0.004 \mathrm{mg} / \mathrm{mL}$ respectively for both analytes.

\section{Linearity}

The correlation coefficient $\left(\mathrm{R}^{2}\right)$ obtained from the linear graph between concentration and peak area was found to be 0.999 for both Lamivudine and its Enantiomer (Table-1, Figure-4) which indicates good linearity of the method for the given range of concentrations.

Table 1: Linearity for results of Lamivudine and its Enantiomer

\begin{tabular}{lcccc} 
& \multicolumn{2}{c}{ Enantiomer } & \multicolumn{2}{c}{ Lamivudine } \\
Level & $\begin{array}{c}\text { Concentration } \\
(\mathrm{mg} / \mathrm{mL})\end{array}$ & Peak area & $\begin{array}{c}\text { Concentration } \\
(\mathrm{mg} / \mathrm{mL})\end{array}$ & $\begin{array}{c}\text { Peak } \\
\text { area }\end{array}$ \\
LOQ & 0.000028 & 1290 & 0.000028 & 1270 \\
50 & 0.0000625 & 2727 & 0.0000625 & 2705 \\
75 & 0.0000938 & 3849 & 0.0000938 & 3988 \\
100 & 0.000125 & 5172 & 0.000125 & 5227 \\
125 & 0.000156 & 6290 & 0.000156 & 6259 \\
150 & 0.000188 & 7497 & 0.000188 & 7571 \\
\hline
\end{tabular}
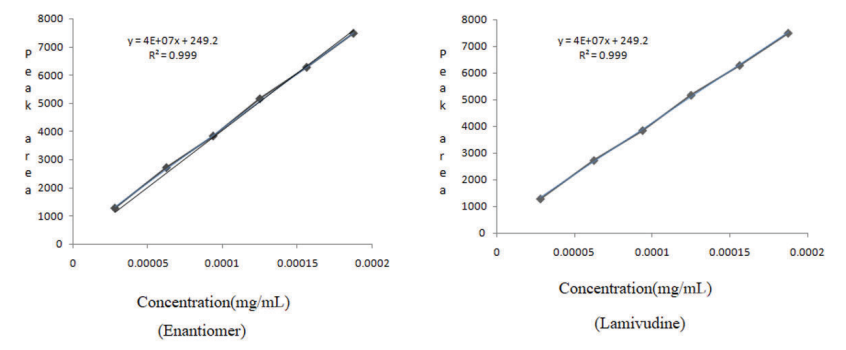

Figure 4: Linearity plot of Enantiomer and Lamivudine. 


\section{Precision}

The precision at LOQ and system precision of the method were assured by assessment of $\%$ RSD values of six replicate injections of Lamivudine and Enantiomer solution at LOQ level and 100 level specifications. Method precision of the method was assured by assessment $\%$ RSD value for the obtained $\%$ assay values of the six individual samples of Lamivudine spiked with Enantiomer at $100 \%$ of the specification limit. The Results (Table-2) represents that the method has adoptable precision as of ICH specifications.

Table 2: Results of various precisions of Lamivudine and its Enantiomer

\begin{tabular}{|c|c|c|c|c|c|}
\hline \multirow[b]{3}{*}{ Injection } & \multirow{2}{*}{\multicolumn{2}{|c|}{$\begin{array}{c}\text { Precision at LOQ } \\
\text { Peak area }\end{array}$}} & \multirow{2}{*}{\multicolumn{2}{|c|}{$\begin{array}{c}\text { System precision } \\
\text { Peak area }\end{array}$}} & \multirow{3}{*}{$\begin{array}{c}\text { Method precision } \\
\% \mathrm{w} / \mathrm{w}\end{array}$} \\
\hline & & & & & \\
\hline & Enantiomer & Lamivudine & Enantiomer & Lamivudine & \\
\hline 1 & 1290 & 1271 & 5238 & 5181 & 0.049 \\
\hline 2 & 1285 & 1316 & 5287 & 5172 & 0.050 \\
\hline 3 & 1283 & 1309 & 5172 & 5227 & 0.051 \\
\hline 4 & 1236 & 1324 & 5269 & 5142 & 0.050 \\
\hline 5 & 1230 & 1247 & 5278 & 5192 & 0.049 \\
\hline 6 & 1241 & 1290 & 5238 & 5154 & 0.050 \\
\hline Mean & 1255 & 1297.2 & 5248.8 & $5177 \cdot 4$ & 0.050 \\
\hline \%RSD & 2.13 & 2.37 & 0.89 & 0.65 & 1.71 \\
\hline
\end{tabular}

\section{Accuracy}

The percentage recovery of the Enantiomer in spiked Lamivudine sample at LOQ, $50 \%, 100 \%$ and $150 \%$ of the working strength of Lamivudine was found to be $100 \pm 2 \%$ and \%RSD observed to be less than 2 (Table 3 ).

Table 3: Results of \% recoveries of the Enantiomer

\begin{tabular}{ccc} 
Level & \%Recovery & \%RSD \\
\hline LOQ & 102.3 & \\
& 102.2 & 0.7 \\
& 101.0 & \\
$50 \%$ & 101.9 & \\
& 100.1 & 1.56 \\
& 98.8 & \\
$100 \%$ & 98.8 & \\
& 100.0 & 1.71 \\
& 102.8 & \\
$150 \%$ & 97.7 & \\
& 97.8 & 0.18 \\
\hline
\end{tabular}

\section{Robustness}

There was no significant change observed in system suitability like relative retention time (RRT) and Resolution by changing flow rate, temperature, and wavelength (Table 4). Hence the method is said to be robust.
Table 4: Results of Robustness of Enantiomer and Lamivudine at different chromatographic conditions

\begin{tabular}{|c|c|c|c|c|}
\hline & Variation & $\begin{array}{l}\text { Condi- } \\
\text { tion }\end{array}$ & RRT & $\begin{array}{l}\text { Resolution } \\
\text { between En- } \\
\text { antiomer and } \\
\text { Lamivudine }\end{array}$ \\
\hline Actual & $\mathrm{O}$ & $\begin{array}{c}0.5 \mathrm{Ml} / \\
\mathrm{min}, \\
30^{\circ} \mathrm{C} \text { and } \\
270 \mathrm{~mm}\end{array}$ & 0.94 & 2.3 \\
\hline \multirow[t]{2}{*}{ Flow rate } & $-10 \%$ & 0.45 & 0.94 & 2.4 \\
\hline & $+10 \%$ & 0.55 & 0.94 & 1.9 \\
\hline \multirow{2}{*}{$\begin{array}{l}\text { Column } \\
\text { Oven tem- } \\
\text { perature }\end{array}$} & $-5^{\circ} \mathrm{C}$ & $25^{\circ} \mathrm{C}$ & 0.94 & 2.4 \\
\hline & $+5^{\circ} \mathrm{C}$ & $35^{\circ} \mathrm{C}$ & 0.94 & 2.0 \\
\hline \multirow[t]{2}{*}{ Wavelength } & $-3 n m$ & $267 \mathrm{~nm}$ & 0.94 & 2.3 \\
\hline & $+3 n m$ & 273nm & 0.94 & 2.3 \\
\hline
\end{tabular}

\section{DISCUSSION}

Proficient and broad searching of the literature reveals that only two HPLC methods have been reported for the determination of Enantiomer in Lamivudine drug substance. Due to long run time with low sensitivity of the reported HPLC methods, which should not be expressed as cost-effective method. To overcome the drawbacks of those HPLC methods, a proficient HPLC method should be required. In the present method, the run time and retention time of the Enantiomer and Lamivudine were low with Lux cellulose-5 (250x $4.6 \mathrm{~mm}, 5 \mu \mathrm{m}$ ) and a mobile phase of $0.1 \%$ Diethyl amine in methanol at a flow rate of $0.5 \mathrm{~mL} / \mathrm{min}$. The present method was economical in comparison with already existed HPLC 
methods less retention time and a simple mobile phase. The outcomes of the validation parameters were confirmed that the projected method has great accuracy, best specificity, and reproducible precision with exceptional sensitivity.

\section{CONCLUSION}

The newly developed method was very effective in the simultaneous estimation of Lamivudine Enantiomer. The results ensure that the method was simple, precise, and accurate. In comparison with the reported method, it has the advantage of high resolution and shorter retention time which makes the method is more acceptable and cost-effective. Hence it can be effectively applied for routine analysis in research institutions, quality control departments in industries, approved testing laboratories.

\section{ACKNOWLEDGEMENTS}

The authors are thankful to the Department of Chemistry, GITAM University, Hyderabad, India for encouragement.

\section{CONFLICT OF INTEREST}

The authors declare that there is no conflict of interest regarding the publication of this article.

\section{FUNDING:}

It is self-financed, no funding was sponsored from any organization, funding agency and non -profit research bodies.

\section{AUTHORS' CONTRIBUTIONS:}

Ms. Siva Jyothi. N has generated the research activity and prepared the manuscript. Dr. Venkatnarayana.M has given guidance and supervision to carry out this research work.

\section{LIST OF ABBREVIATIONS}

RT: Retention Time

LOD: Limit of Detection

LOQ: Limit of Quantification

ICH: International Conference on Harmonization

SD: Standard Deviation

RSD: Relative Standard Deviation

RRT: Relative retention Time

\section{REFERENCES}

1. Luo A, Jiang $X$ and Ren H. Lamivudine therapy for chronic hepatitis B in children: a meta-analysis. Virol J. 2019;16(1):88.

2. Luo A, Jiang $X$, and Ren H. Lamivudine plus tenofovir combination therapy versus lamivudine monotherapy for HBV/HIV coinfection: A meta-analysis. Virol J. 2018;15(1):139.

3. Quercia R, Perno C-F, Koteff J, Moore K, McCoig C, Clair M et al. Twenty-Five Years of Lamivudine: Current and Future Use for the Treatment of HIV-1 Infection. J Acquir Immune Defic Syndr. 2018;78(2):125-135.

4. Mallikarjuna RN, Gowri SD. Development and validation of stability-indicating HPLC method for simultaneous determination of Lamivudine, Tenofovir, and Dolutegravir in bulk and their tablet dosage form. Future J Pharm Sci. 2015; 1(2):73-77.

5. Bhavsar DS, Patel BN, and Patel CN. RP-HPLC method for simultaneous estimation of tenofovir disoproxil fumarate, lamivudine, and efavirenz in the combined tablet dosage form. Pharm Meth. 2012; 3(2):73-78.

6. Karishma S, Subramaniam S, Muthuraman M and Sivasubramanian A. RP-HPLC analytical method development and validation for lamivudine and zidovudine in pharmaceutical dosage forms. Int J Pharmtech Res. 2013; 5:1321-1331.

7. Nalini CN, Nithya A, Afreen A, Banu AA, Hemalatha P and Gayathri EJ. Analytical Methods for Determination of Lamivudine and their Applicability in Biological Studies. Research J Pharm and Tech. 2018; 11(11):5166-172.

8. Godela R and Sowjanya G. An effective stability indicating RPHPLC method for simultaneous estimation of Dolutegravir and Lamivudine in bulk and their tablet dosage form. Future J Pharm Sci. 2020; 6:1-9.

9. Nekkala K, Kumar VS and Ramachandran D. Development and Validation for the Simultaneous Estimation of Lamivudine, Tenofovir Disproxil and Dolutegravir In Drug Product by RPHPLC. J Pharm Sci Res. 2017 Sep 1; 9(9):1505.

10. Nandi U, Das A, Roy B, Choudhury H, Gorain B and Pal TK. Development and validation of an HPLC-UV method for simultaneous determination of zidovudine, lamivudine, and nevirapine in human plasma and its application to a pharmacokinetic study in human volunteers. Drug Test Anal. 2013;5(6):485-91.

11. Subbarao M, Ramakrishna M and Mogilireddy D. Chiral separation of lamivudine enantiomer by HPLC using cellulose tris (3,5-dichlorophenylcarbamate) as a chiral stationary phase. Indo Am J Pharm. 2016; 6(5).

12. The International Conference on Harmonization, Q2 (R1), (2005). https://www.ich.org/page/quality-guidelines

13. The International Conference on Harmonization, Q1 (A) R2, (2003).

14. https://www.ich.org/page/quality-guidelines. 